\title{
Simulation \& Optimization of the Gear System of a 6-DOF Manipulator Using Flexible Dynamic of ANSYS
}

\author{
Bin $\mathrm{Li}^{*}{ }^{1,2}$, Xifan $\mathrm{Yao}^{1}$, Yongxiang $\mathrm{Li}^{1}$, Wei Tan ${ }^{1}$, Huidong $\mathrm{Lou}^{1}$ and Dongyuan $\mathrm{Ge}^{1}$ \\ ${ }^{I}$ School of Mechanical \& Auto Engineering, South China University of Technology Guangzhou. 510640, China \\ ${ }^{2}$ Department of Mechanical Engineering, Guangdong University of Petrochemical Technology, Maoming, 525000, \\ Guangdong Province, China
}

\begin{abstract}
This paper presents a novel way for a structural dynamic simulation analysis on a three-dimensional (3-D) finite element (FE) model of a 6-DOF Manipulator using ANSYS Workbench 13.0 that allows integrated optimization. The load between driving and driven gear is delivered by elastic frictional contact, which leads to some non-liner contact problems, and the contact problems are solved according to the FE parametric programming method. This study particularly focused on investigating static, dynamic, and fatigue behaviors of the gear system in a 6-DOF robot mechanism, which is modeled using SolidWorks software. Moreover, the ANSYS Workbench was used to determine the stress distribution, deformation and fatigue behaviors of the mechanism, and finally to carry out the optimization simulation analysis of its materials together with structural geometry. As a result, the design experience accumulated will be very useful for the future product design in terms of guidelines for even more complex mechanical systems or more complex boundary conditions.
\end{abstract}

Keywords: Interpolation, Nonlinear, Optimization, Prototype, Simulation, Finite element.

\section{INTRODUCTION}

Normally, the design process of a robot falls into: kinematic optimization, dynamic optimization, and control system design. Kinematic optimization aims at mechanical structure, whereas dynamic optimization aims at defining critical ones which lead the structure to subject to maximum stress and choosing materials, geometry etc., and control system design aims at picking speed and movement's precision and smoothness [1].

This paper mainly analyzes dynamic optimization of a 6DOF robot (the physical model is shown in Fig. 1), which is based on its prototype model, as to materials, geometry etc. This study focuses on the effect of the gears, while the effects of manufacturing and assembly errors are included, too.

\section{NONELINER CONTACT ANALYSIS}

\subsection{Simulation Model}

3-D finite element analysis (FEA) has been widely used to examine the effects of the static and dynamic loads on the critical zones of a structure. Additionally, a well-known solid modeling software, SolidWorks (the simulation model using solidworks is shown in Fig. (2)), was used to design the basic parts of the 6-DOF robot, together with ANSYSWorkbench (the finite element model is shown in Fig. (3)) to

*Address correspondence to this author at the School of Mechanical \& Auto Engineering, South China University of Technology Guangzhou. 510640, China; Tel: 0086-668-2923563; Fax: 0086-668-2923563;

E-mail: guangzhoulibin@126.com assess their physical features, working properties, and optimization, and the FEA stress analysis and failure analysis outcomes were taken into consideration.

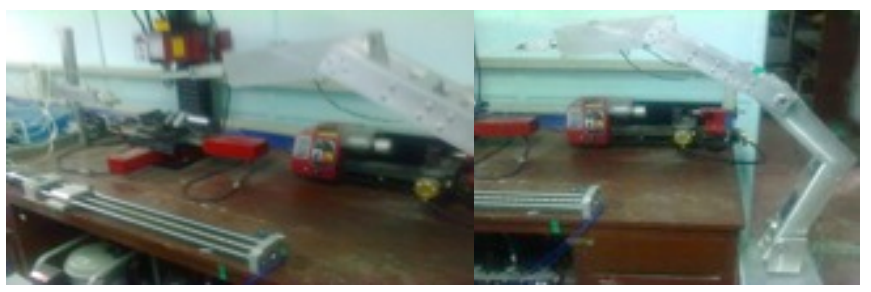

Fig. (1). Physical model.

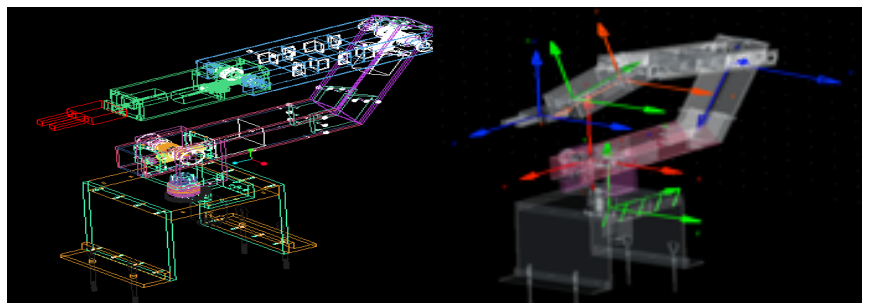

Fig. (2). Simulation model on SolidWorks.

2.2. Dynamic Crash Simulation Analysis of the Gear System Mechanism Using ANSYS/Workbench

ANSYS/Workbench is an efficient FEA tool in engineering. In this paper, ANSYS/Workbench was used to study the working-state of some parts of transmission system from a 6-DOF robot, where the gears (including wormgears) had been assigned with nonlinear material behavior of structural steel, and other parts had been assigned with aluminum alloy. The FEM of the gears consisted of total 
237,544 nodes, and 139,836 elements. The gears were modeled with non-linear flexible material of structure steel, whose Young's modulus $\mathrm{E}=2 \mathrm{e}+11 \mathrm{~Pa}$, poisson's ratio m $=0.3$, and density $d=7850 \mathrm{~kg} / \mathrm{m} 3$. And the others (like structural parts etc.) were modeled with a material of aluminum alloy, whose Young's modulus $\mathrm{E}=0.7 \mathrm{e}+11 \mathrm{~Pa}$, poisson's ratio $\mathrm{m}=0.31$, and density $d=2770 \mathrm{~kg} / \mathrm{m} 3$. Some constrain sets had been created from the contact surface and the rotate moment of the driving gears were accepted as $\mathrm{M}=$ 100 N.mm.

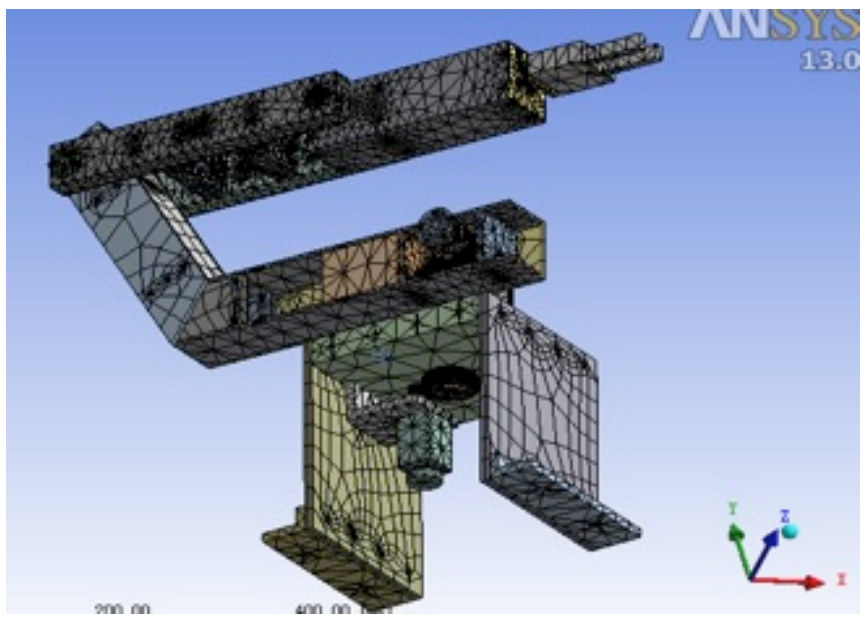

Fig. (3). Simulation model on WorkBench.

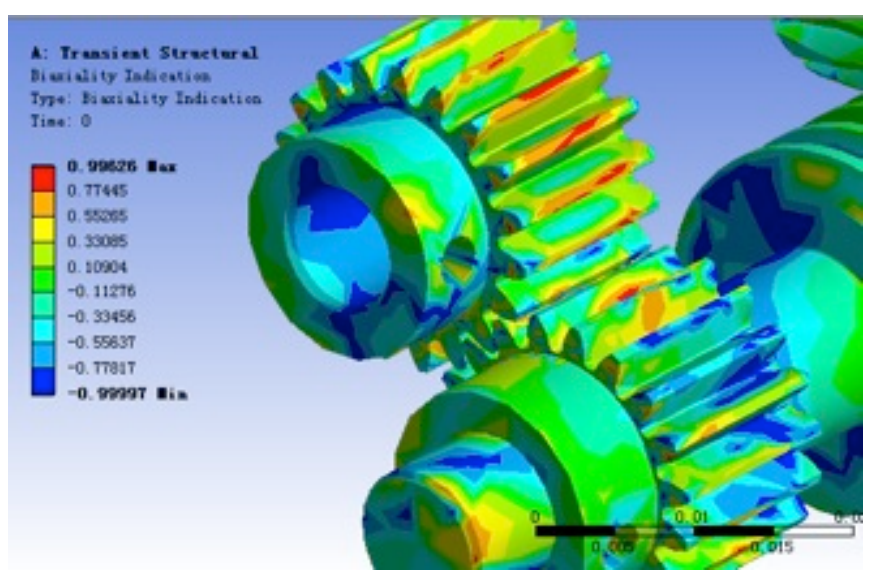

Fig. (4). Biaxiality indication.

From the finite element analysis, biaxiality indication from Fig. (4) shows that critical zones were presented at contact faces, and these zones exposed to dynamic overloading will cause plastic deformation, higher stresses, material failures even with low-cycle loadings. Accordingly, in a further study, a fatigue analysis was carried out.

\subsection{Fatigue Analysis of the Gear System Using ANSYS Workbench}

All components have a finite life, and it is estimated that $50 \sim 90 \%$ of structural failure is due to fatigue [2], typically resulted from stress, wear and failures caused by flaws in the material, poor or inconsistent manufacturing processes, complex geometries, etc. [3]. The FEA software of ANSYS Workbench was used to obtain the fatigue life, factor of safety and damage distribution.

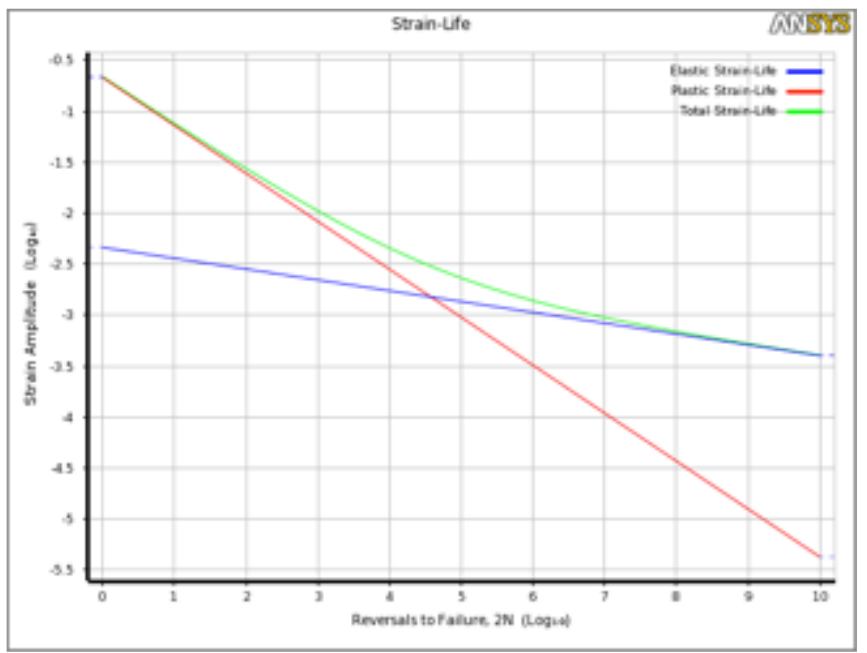

Fig. (5). Strain-life for structural steel.

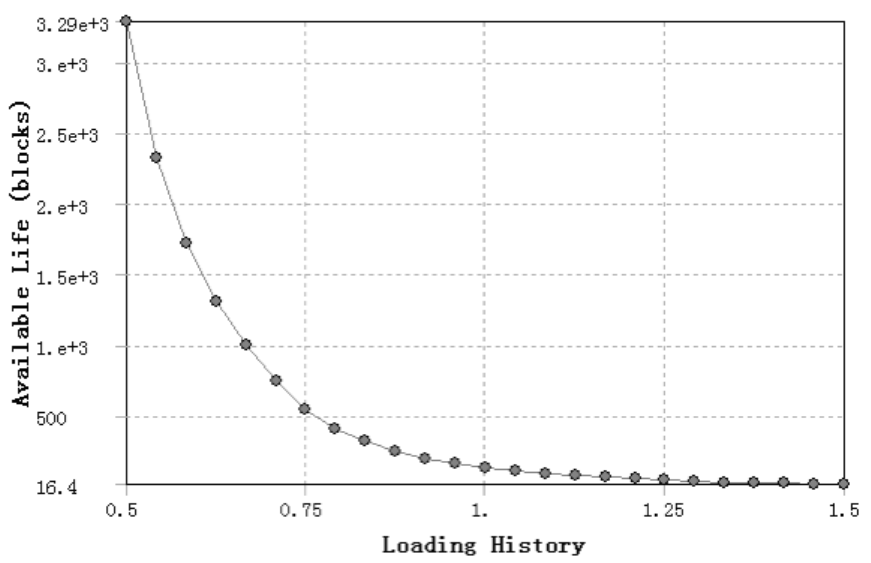

Fig. (6). Non-constant amplitude load history data from fatigue analysis Strain-life for structural steel.

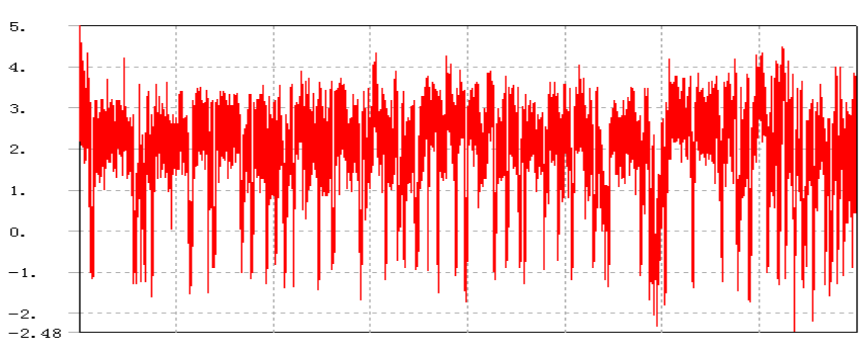

Fig. (7). Available life $v s$ loading history.

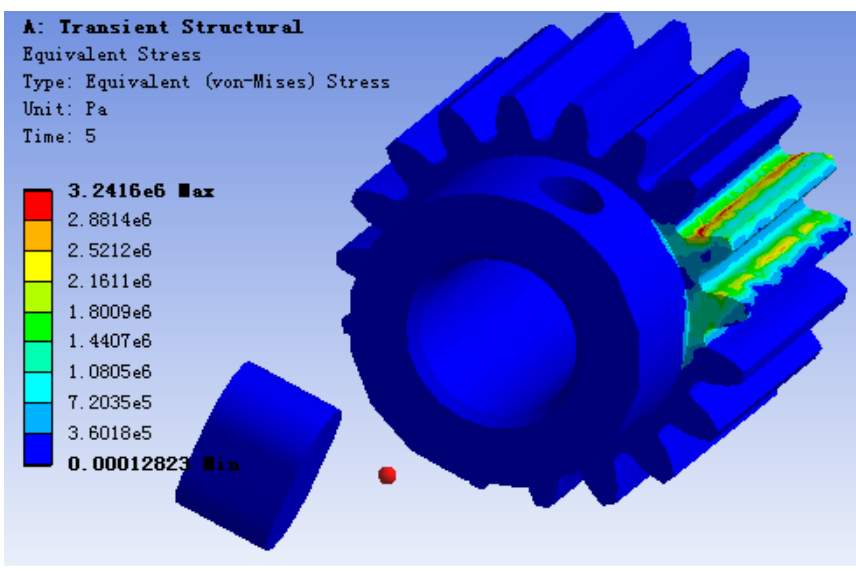

Fig. (8). Von-Misses stresses distribution. 


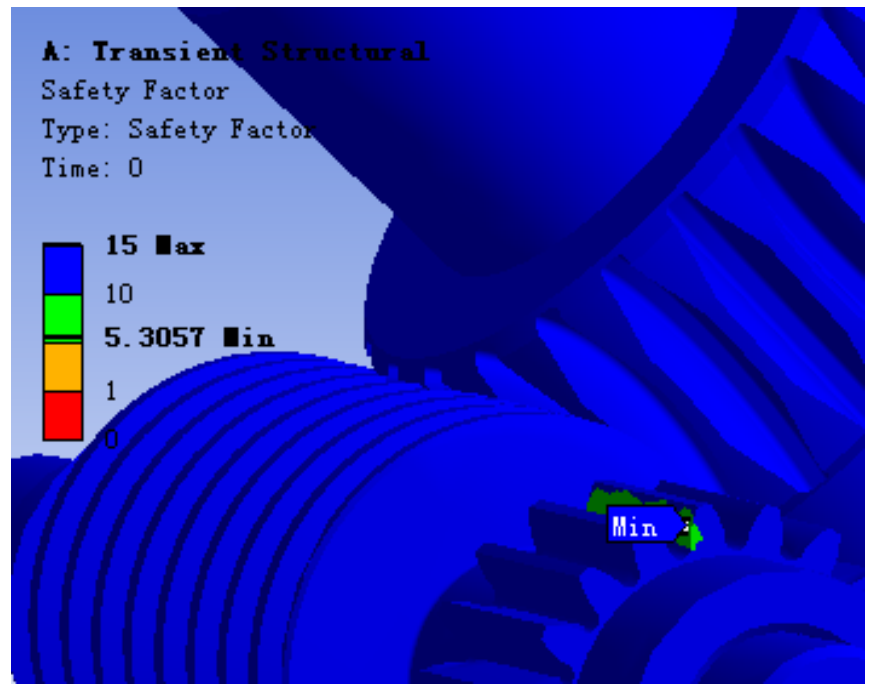

Fig. (9). Safety factor distribution.

Fig. (5) indicates the strain life curve of structural steel material, and the amplitude load history data from fatigue analysis is shown by Fig. (6). Fig. (7) shows the available life (the number of cycles) of the gear system under constant loading until failing. And the fatigue analysis was performed with infinite life criteria $(\mathrm{N}=1 \mathrm{e} 9$ cycle) and safety factor of 0.85, which obtained the Von-Misses stresses distribution as shown in Fig. (8). Fig. (9) shows the safety factor within a fatigue failure at a given design life. This value varies between the minimum safe zones (0) to maximum safe zones (15). As it can be seen from this figure, minimum safety of the design (5.3057) designates the critical zones, which are the contact zones of gears.

\section{OPTIMUM DESIGN OF THE ANALYSIS}

In this study, Kriging interpolation response optimization method is used.

\subsection{Kriging Algorithms}

Kriging interpolation method is named after a mining engineer, D. G. Krige from South African, which has been applied onto optimization problems, and has been proved more reliable than other methods for those highly nonlinear contact problems since 1990s [4-6].

Kriging postulates a combination of a global model plus local deviation [7], which is shown as follows [8]:

$y(x)=f(\delta, x)+\beta(x)$

where $y(x)$ is the unknown function of interest, and $f(\delta, x)$, as a regression model, is a polynomial function of $x$, which is similar to the polynomial model in a response surface and provides a "global" model of the design space, and it can be written as:

$$
\begin{aligned}
& f(\delta, x)=\delta_{1} f_{1}(x)+\delta_{2} f_{2}(x)+\cdots+\delta_{m} f_{m}(x) \\
& =\left[f_{1}(x) f_{2}(x) \cdots f_{m}(x)\right] \delta /=f(x)^{T} \delta
\end{aligned}
$$

where $\delta$ is the regression model parameter, and $\beta(x)$ is a covariance-stationary process $[9,10]$, which has the following statistical properties:
$E[\beta(x)]=0, / \operatorname{Var}[\beta(x)]=\sigma^{2}$,

$E\left[\beta\left(x^{i}\right), \beta\left(x^{j}\right)\right]=\sigma^{2} \cdot R\left(\theta_{k}, x_{k}{ }^{i}, x_{k}{ }^{j}\right)$,

where $R\left(\theta_{k}, x_{k}^{i}, x_{k}^{j}\right)$ is the correlation vector model between parameter $\theta_{k}$, observed spatial points and sample points $\left\{x^{1}, \ldots, x^{n_{s}}\right\}, f(x)$ "globally" approximates the design space, $\beta(x)$ creates "localized" deviations, and the covariance matrix of $\beta(x)$ is given by

$\beta(x)=\sum_{i=1}^{N} \lambda_{i} r\left(x^{i}, x^{j}\right) \operatorname{Cov}\left[\beta\left(x^{i}\right), \beta\left(x^{j}\right)\right]=\sigma^{2} R\left(\left[r\left(x^{i}, x^{j}\right)\right]\right)$

where $\mathrm{R}$ is a correlation matrix, an $\mathrm{N}^{*} \mathrm{~N}$ symmetric and positive definite matrix with ones along the diagonal, and $r\left(x^{i}, x^{j}\right)$ is the spatial correlation of the function between any two of the $\mathrm{N}$ sample points $x^{i}$ and $x^{j}$, which uses Gaussian correlation function as follows:

$r\left(x^{i}, x^{j}\right)=\exp \left(-\sum_{k=1}^{M} \theta_{k}\left|x_{k}^{i}-x_{k}^{j}\right|^{2}\right)$

where $M$ is the number of design variables, $\theta_{k}$ are the unknown parameters fitting the model, and $x_{k}^{i}$ and $x_{k}^{j}$ are the $k$ th components of sample points $x^{i}$ and $x^{j}$.

And thus the estimated value of $y(x)$ can be gotten from the following formula:

$\hat{y}(x)=f_{0}+r^{T}(x) R^{-1} y(x)-\hat{\beta}$

where $\hat{y}(x)$ is the column vector with a length of $n_{s}$, which includes the approximate response data from $y(x)$. And $y(x)$ will be a unit column vector when $f(x)$ is simplified into a constant $f_{0}$,

When using the linear weighted superposition interpolation of the response $y_{i}$ for sample data $x_{i}$, another response model of observed data can be obtained as follows:

$\hat{y}(x)=c(x)^{T} y(x)$,

While as the unknown weight coefficient vector, $c(x)^{T}=\left[c_{1}, c_{2} \cdots c_{n}\right]^{T}$,

And the error between the estimated $\hat{y}(x)$ and $y(x)$ is:

$$
\begin{aligned}
& \hat{y}(x)-y(x)=c(x)^{T} y(x)-y(x) \\
& =c(x)^{T}[f(\delta, x)+\beta(x)]-\left[f(x)^{T}+\beta\right] \\
& =c(x)^{T} \beta-\beta+\left[c f(x)^{T}-f(x)\right]^{T}
\end{aligned}
$$

To minimize the error, let $c f(x)^{T}-f(x)=0$, so the expectation variance for the estimated model would be:

$$
\begin{aligned}
& E\left[(\hat{y}(x)-y(x))^{2}\right]=E\left[\left(c(x)^{T} \beta-\beta\right)^{2}\right] \\
& =\sigma^{2}\left(1-2 c^{T} r+c^{T} R c\right)
\end{aligned}
$$


To obtain the extreme value for (9), Lagrange multiplier method was used:

$$
L(x, \lambda)=\sigma^{2}\left(1-2 c^{T} r+c^{T} R c\right)-\lambda\left(f^{T} c-f\right)
$$

To solve it, Kriging equations can be gotten:

$\left[\begin{array}{ll}R & f \\ f^{T} & 0\end{array}\right]\left[\begin{array}{l}c \\ \tilde{\lambda}\end{array}\right]=\left[\begin{array}{l}r \\ f\end{array}\right]$

And the solution for the equations are:

$$
\left\{\begin{array}{c}
\tilde{\lambda}=\left(f^{T} R^{-1} f\right)^{-1}\left(f^{T} R^{-1} r-f\right)^{T} \\
c=R^{-1}(r-f \tilde{\lambda})
\end{array}\right.
$$

where $\tilde{\lambda}=-\lambda / 2 \sigma^{2}$.

Now substitute (12) into (7), then there will be:

$\hat{y}(x)=r^{-1} R^{-1} y-$

$\left(f^{T} R^{-1} r-f\right)^{T} \cdot\left(f^{T} R^{-1} f\right)^{-1} f^{T} R^{-1} y$

And let $f \delta \cong y$, the least square estimation of $\delta$ would be:

$\delta^{*}=\left(f^{T} R^{-1} f\right)^{-1} f^{T} R^{-1} y$

Then plug (14) into (13), there will be:

$\hat{y}(x)=r^{-1} R^{-1} Y-\left(f^{T} R^{-1} r-f\right)^{T} \delta^{*}$

$=f^{T} \delta^{*}+r^{-1} R^{-1}\left(y-f \delta^{*}\right) \equiv f(x)^{T} \delta^{*}+r(x)^{T} \gamma^{*}$

where $\gamma^{*}=R^{-1}\left(y-f \delta^{*}\right)$.

Thus the expectation variance could be gotten:

$\eta(x)=\sigma^{2}\left(1+\tilde{\lambda} F^{T} R^{-1} F \tilde{\lambda}-r^{T} R^{-1} r\right)$,

If the observed data given, $\delta^{*}$ and $\gamma^{*}$ will be obtained as long as we obtain the solution of $f(x)$ and $r(x)$ when $c=R^{-1}(r-f \tilde{\lambda})$ is fitted into (9).

$\delta$ can be simplified into a unit column vector assumed that $f$ be a constant, and its estimated variance could be:

$\delta^{2}=(y-f \delta)^{T} R^{-1}(y-f \delta) / n_{s}$

So the accuracy of the regression model is not influenced significantly by the order of the model. Thus once the regression model and correlation model are settled, the parameters of $\delta^{*}$ and $\gamma^{*}$ obtained from the correlation matrix $R$ could just depend on the unknown correlation parameters of $\left\{\theta_{k}>0, k=1,2, \cdots, n\right\}$, which are calculated by maximum likelihood method as follows:

maximize $\rho=-\left[n_{s} \ln \left(\hat{\sigma}^{2}\right)+\ln (|R|)\right] / 2$,

which is utilized to determine the optimum parameters for obtaining the Kriging model.

\subsection{Optimization of Design}

In this study, as shown in Fig. (10), the volumes and masses of gears, applied moments, and safety-factors of the parts were selected as the design points or parameters. Therefore, minimization of the masses of the gear structure case is done by limiting the safety-factor with the applied moment. In order to investigate the structural performance and masses savings of the structure with the changes of applied moment, the analysis for optimal size was performed for two different applied moments

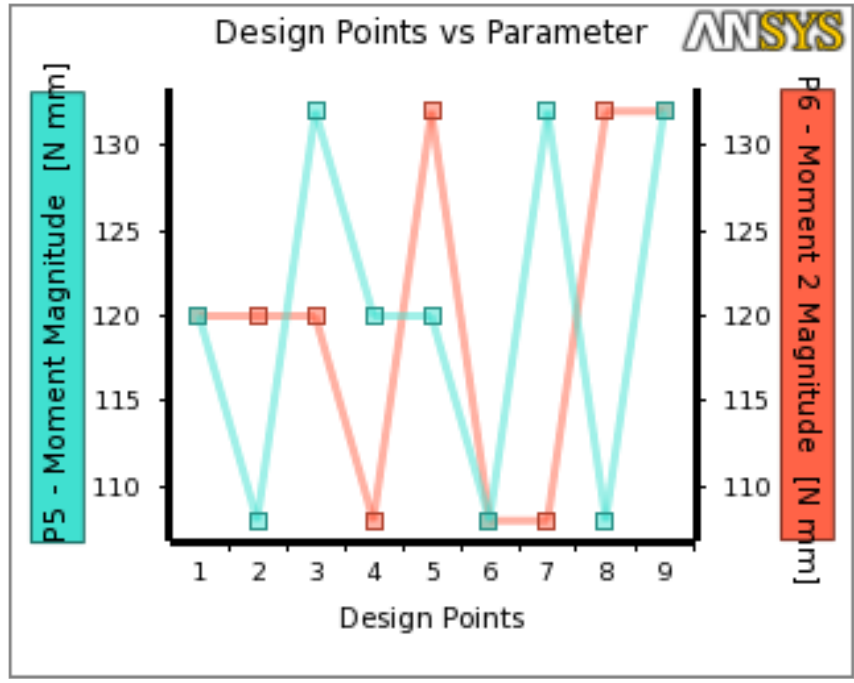

Fig. (10). Design points $v s$ parameters.

\subsubsection{Material Optimization}

The s-n curves for copper alloy and structural steel as shown in Fig. (11), were chosen as comparison materials to find which one better meets operation specifications by waist, and shoulder parts were also taken into account. Then using stress and fatigue analysis, here the gears from mechanical properties of the gears of both materials are shown in Fig. (12). If copper alloy material applied 0.21941 $\mathrm{kg}$ weight on the part of "yaodrivengear", while structural steel material applied, $0.20751 \mathrm{~kg}$ on it. And from the Newton's second law: F=m.a, the load will increase when mass is added if "a" is determined, which will lead to the increase inertia, and the result is shown in Fig. (12). As to this, the material of structural steel will meet the specifications of the structure a little better.

Safety factor from stress analysis in Fig. (13) shows the minimum stress occurs at the part of "yaodrivinggear": the factor is greater than 10 when copper alloy material is applied, and the minimum stress of 3.6495 occurs when structural steel material applied. From this point, copper alloy will better meet the specifications.

As shown in Fig. (14), there is another different result from equivalent stress analysis for structural steel and copper alloy respectively: maximum stress of $68.503 \mathrm{Mpa}$ for structural steel and $3.3341 \mathrm{MPa}$ for copper alloy, and both occur on the part of "yaodrivengear". And for this, again copper alloy will better meet the performance specifications.

Rainflow matrix and Damage matrix shown in Figs. (15, 16) both from fatigue analysis, show the minimum stress occurs on the parts when copper alloy is applied. Both figures show that the minimum mean stress is $8.232 \mathrm{MPa}$, 

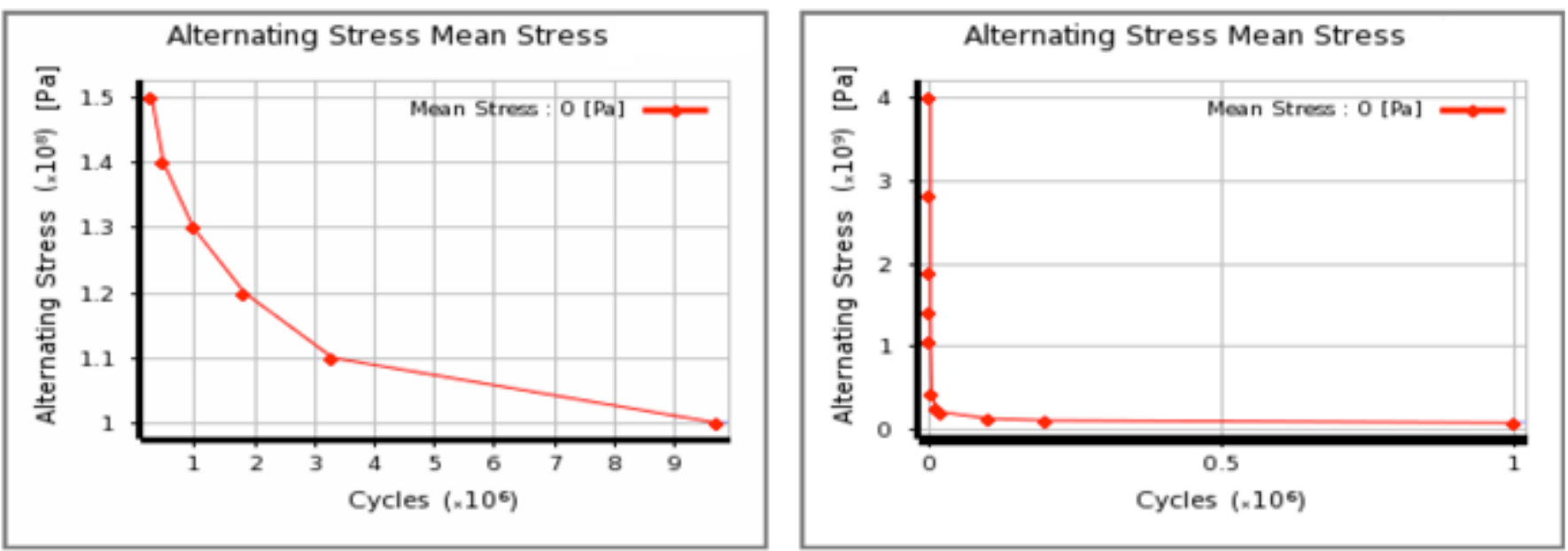

\section{a)s-n curve for copper-alloy}

b)s-n curve for structural steel

Fig. (11). s-n curves (M=100n.s and 120n.s).

\begin{tabular}{|c|c|c|c|c|c|c|}
\hline Object Name & jianworm & jianwormwheel & jiandrivinggeat & jiandrivengear & yaodrivinggear & yaodrivengear \\
\hline \multirow{2}{*}{\multicolumn{7}{|c|}{$\begin{array}{l}\text { Copper Alloy } \\
\text { Properties }\end{array}$}} \\
\hline & & & & & & \\
\hline Volume & $19858 \mathrm{~mm}^{3}$ & $9245 . \mathrm{mm}^{3}$ & $3694.8 \mathrm{~mm}^{3}$ & 3423. $\mathrm{mm}^{3}$ & $3917.7 \mathrm{~mm}^{3}$ & $26435 \mathrm{~mm}^{3}$ \\
\hline Mass & $0.16482 \mathrm{~kg}$ & $\begin{array}{c}7.6734 \mathrm{e}-002 \\
\mathrm{~kg}\end{array}$ & $2.9004 \mathrm{e}-002 \mathrm{kc}$ & $\underset{\mathrm{kg}}{2.8411 \mathrm{e}-002}$ & $3.2517 \mathrm{e}-002 \mathrm{~kg}$ & $0.21941 \mathrm{~kg}$ \\
\hline $\begin{array}{r}\text { Moment of Inertia } \\
\text { Ip1 }\end{array}$ & $\begin{array}{l}72.991 \\
\mathrm{~kg} \cdot \mathrm{mm}^{2}\end{array}$ & $8.9227 \mathrm{~kg} \cdot \mathrm{mm}^{2}$ & $1.5653 \mathrm{~kg} \cdot \mathrm{mm}^{2}$ & $1.6252 \mathrm{~kg} \cdot \mathrm{mm}^{2}$ & $1.4856 \mathrm{~kg} \cdot \mathrm{mm}^{2}$ & $50.228 \mathrm{~kg} \cdot \mathrm{mm}^{2}$ \\
\hline $\begin{array}{r}\text { Moment of Inertia } \\
\text { Ip2 }\end{array}$ & $\begin{array}{l}72.982 \\
\mathrm{~kg} \cdot \mathrm{mm}^{2}\end{array}$ & $8.9238 \mathrm{~kg} \cdot \mathrm{mm}^{2}$ & $1.5765 \mathrm{~kg} \cdot \mathrm{mm}^{2}$ & $1.6356 \mathrm{~kg} \cdot \mathrm{mm}^{2}$ & $1.4867 \mathrm{~kg} \cdot \mathrm{mm}^{2}$ & $50.433 \mathrm{~kg} \cdot \mathrm{mm}^{2}$ \\
\hline $\begin{array}{r}\text { Moment of Inertia } \\
\text { Ip3 }\end{array}$ & $\begin{array}{c}7.939 \\
\mathrm{~kg} \cdot \mathrm{mm}^{2}\end{array}$ & $10.556 \mathrm{~kg} \cdot \mathrm{mm}^{2}$ & $1.5397 \mathrm{~kg} \cdot \mathrm{mm}^{2}$ & $1.5656 \mathrm{~kg} \cdot \mathrm{mm}^{2}$ & $1.4591 \mathrm{~kg} \cdot \mathrm{mm}^{2}$ & $94.474 \mathrm{~kg} \cdot \mathrm{mm}^{2}$ \\
\hline
\end{tabular}

\section{a) structural steel}

\begin{tabular}{|c|c|c|c|c|c|c|}
\hline Object Name & jianworm & jianwormwheel & jiandrivengear & jiandrivinggear & yaodrivinggear & yaodrivengear \\
\hline \multicolumn{7}{|c|}{ Structural Steel } \\
\hline \multicolumn{7}{|c|}{ Properties } \\
\hline Volume & $19858 \mathrm{~mm}^{3}$ & 9245. $\mathrm{mm}^{3}$ & 3423. $\mathrm{mm}^{3}$ & $3694.8 \mathrm{~mm}^{3}$ & $3917.7 \mathrm{~mm}^{3}$ & $26435 \mathrm{~mm}^{3}$ \\
\hline Mass & $0.15588 \mathrm{~kg}$ & $\begin{array}{c}7.2573 \mathrm{e}-002 \\
\mathrm{~kg}\end{array}$ & $\begin{array}{c}2.6871 \mathrm{e}-002 \\
\mathrm{~kg}\end{array}$ & $2.9004 \mathrm{e}-002 \mathrm{~kg}$ & $3.0754 \mathrm{e}-002 \mathrm{~kg}$ & $0.20751 \mathrm{~kg}$ \\
\hline $\begin{array}{r}\text { Moment of Inertia } \\
\text { Ip1 }\end{array}$ & $\begin{array}{l}69.033 \\
\mathrm{~kg} \cdot \mathrm{mm}^{2}\end{array}$ & $8.439 \mathrm{~kg} \cdot \mathrm{mm}^{2}$ & $1.5371 \mathrm{~kg} \cdot \mathrm{mm}^{2}$ & $1.4804 \mathrm{~kg} \cdot \mathrm{mm}^{2}$ & $1.405 \mathrm{~kg} \cdot \mathrm{mm}^{2}$ & $47.505 \mathrm{~kg} \cdot \mathrm{mm}^{2}$ \\
\hline $\begin{array}{r}\text { Moment of Inertia } \\
\text { Ip2 }\end{array}$ & $\begin{array}{l}69.025 \\
\mathrm{~kg} \cdot \mathrm{mm}^{2}\end{array}$ & $8.44 \mathrm{~kg} \cdot \mathrm{mm}^{2}$ & $1.547 \mathrm{~kg} \cdot \mathrm{mm}^{2}$ & $1.4911 \mathrm{~kg} \cdot \mathrm{mm}^{2}$ & $1.4061 \mathrm{~kg} \cdot \mathrm{mm}^{2}$ & $47.698 \mathrm{~kg} \cdot \mathrm{mm}^{2}$ \\
\hline $\begin{array}{r}\text { Moment of Inertia } \\
\text { Ip3 }\end{array}$ & $\begin{array}{l}7.5085 \\
\mathrm{~kg} \cdot \mathrm{mm}^{2}\end{array}$ & $9.9838 \mathrm{~kg} \cdot \mathrm{mm}^{2}$ & $1.4807 \mathrm{~kg} \cdot \mathrm{mm}^{2}$ & $1.4562 \mathrm{~kg} \cdot \mathrm{mm}^{2}$ & $1.38 \mathrm{ka} \cdot \mathrm{mm}^{2}$ & $89.352 \mathrm{~kg} \cdot \mathrm{mm}^{2}$ \\
\hline
\end{tabular}

\section{b) copper alloy}

Fig. (12). Mechanical properties of the part material.

maximum mean stress is $16.53 \mathrm{MPa}$ when copper alloy applied; and the minimum is $169.5 \mathrm{MPa}$, the maximum is 342.2 MPa when structural steel applied. Fig. (16) also shows the relative damage is $0.00 \% \sim 6.31 \%$ for structural steel, and it is only $0.00 \% \sim 0.63 \%$ for copper alloy. From this point, copper alloy will better meet the performance. According to the first analysis of inertia moment, although the parts made from structural steel work better, but the difference is very 


\begin{tabular}{|r|c|}
\hline \multicolumn{2}{|c|}{ Definition } \\
\hline Type & Safety Factor \\
\hline Results \\
\hline Minimum & 3.6495 \\
\hline Minimum Occurs On & yaodrivengear \\
\hline
\end{tabular}

a) structural steel

\begin{tabular}{|r|c|}
\hline \multicolumn{2}{|c|}{ Definition } \\
\hline Type & Safety Factor \\
\hline Results \\
\hline Minimum & $>10$ \\
\hline Minimum Occurs On & yaodrivinggear \\
\hline
\end{tabular}

b) copper alloy

Fig. (13). Safety factor of the part.

\begin{tabular}{|r|c|}
\hline \multicolumn{2}{|c|}{ Definition } \\
\hline \multicolumn{2}{|c|}{ Type Equivalent (von-Mises) Stress } \\
\hline Results \\
\hline Minimum & $1.0994 \mathrm{e}-010 \mathrm{MPa}$ \\
\hline Maximum & $68.503 \mathrm{MPa}$ \\
\hline Minimum Occurs On & jianworm \\
\hline Maximum Occurs On & yaodrivengear \\
\hline
\end{tabular}

\section{a) structural steel}

Fig. (14). Equivalent stress of the part.

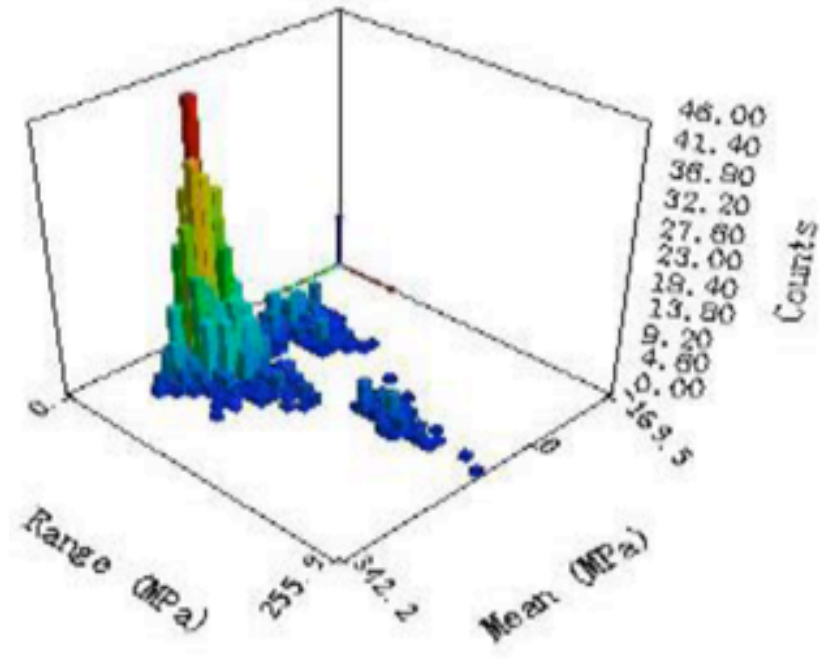

\section{a) structural steel}

Fig. (15). Rainflow matrix for the scoped parts.

tiny, which could be ignored. And in all the other cases, like the stress analysis of safety factor, equivalent stress analysis, or fatigue analysis, the parts made from copper alloy have a much better performance. Based from the overall on balance, we chose copper alloy for these parts, as well as the basis for the following optimization step.

\subsubsection{Shape Optimization}

The purpose of the shape optimization analysis is typically to optimize the distribution of a material for a normally to minimize mass for this simulation model, and

\begin{tabular}{|r|c|}
\hline \multicolumn{2}{|c|}{ Definition } \\
\hline \multicolumn{2}{|c|}{ Type Equivalent (von-Mises) Stress } \\
\hline Minimum & $2.1165 \mathrm{e}-010 \mathrm{MPa}$ \\
\hline Maximum & $3.3341 \mathrm{MPa}$ \\
\hline Minimum Occurs On & jianworm \\
\hline Maximum Occurs On & jiandrivengear \\
\hline
\end{tabular}

b) copper alloy

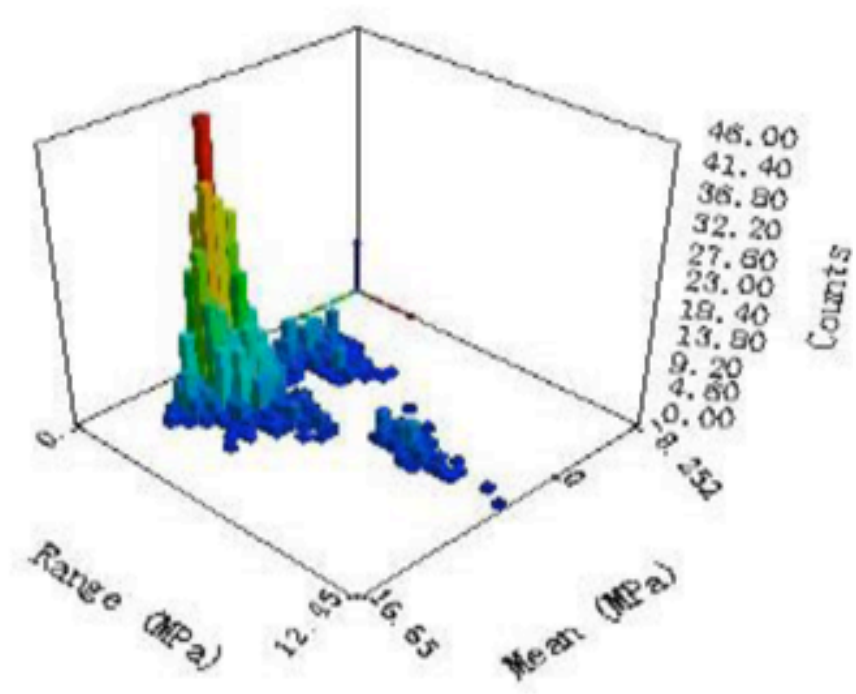

b) copper alloy

the structural parts of gear system were taken into consideration. Mass optimization is an iterative process. The iterative process starts out with a determined mass, and a safety factor to check if the maximum stress or strain exceeds desired levels. Then eliminating the mass and pinpointing another safety-factor to check if the maximum stress or strain is reduced to the reasonable levels, otherwise the iterative process repeats till the result is reasonable. Fig. (17) shows the removable mass distribution (red region) when the target mass is set to reduce to $50 \%$ for copper alloy. In this model, the original mass of the part is 1.5574 


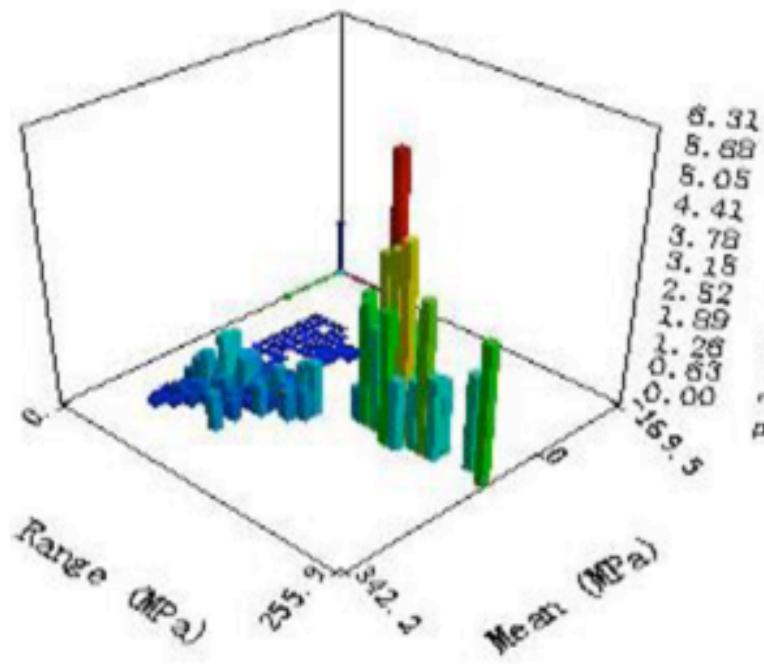

a) structural steel

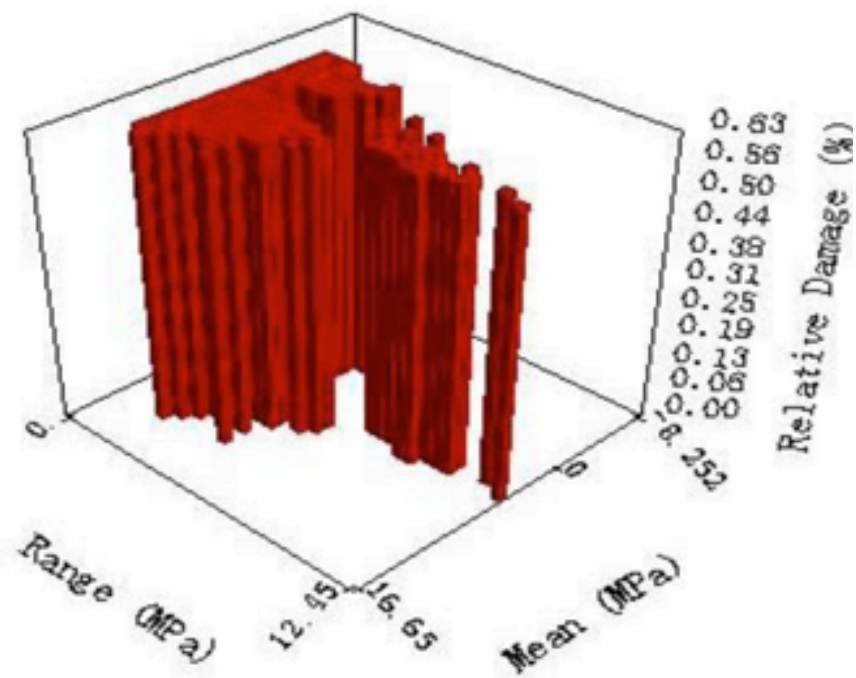

b) copper alloy

Fig. (16). Damage matrix for the scoped parts.

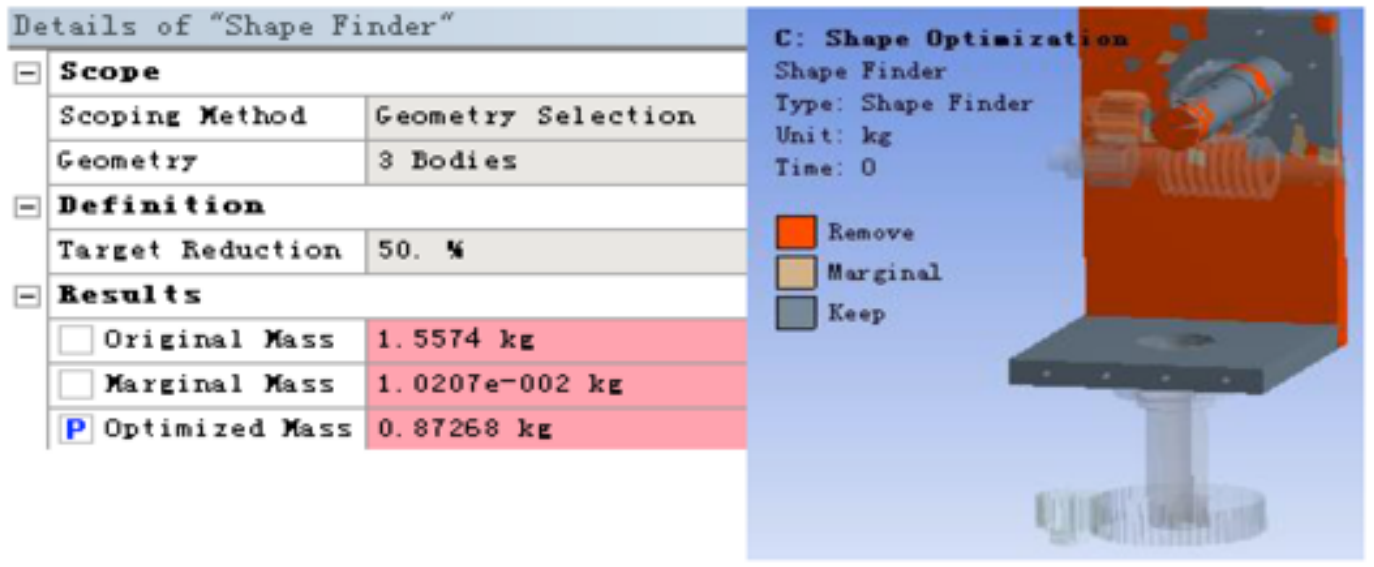

Fig. (17). Removable mass distribution.

$\mathrm{kg}$, and the optimized mass is $0.87268 \mathrm{~kg}$. But the result as shown in Fig. (18) indicates that the stress increased instead (the stress was $3.3341 \mathrm{Mpa}$ before the mass being optimized).

\begin{tabular}{|r|c|}
\hline \multicolumn{2}{|c|}{ Definition } \\
\hline Type & Equivalent Alternating Stress \\
\hline Design Life & $1 . e+009$ cycles \\
\hline Results \\
\hline Minimum & $1.5547 \mathrm{e}-010 \mathrm{MPa}$ \\
\hline Minimum Occurs On & jianworm \\
\hline Maximum & $4.184 \mathrm{MPa}$ \\
\hline Maximum Occurs On & jiandrivengear \\
\hline
\end{tabular}

Fig. (18). Equivalent stress of the optimized part.

Theoretically, it is to reduce mass to optimize the shape of parts. But in this case, it is not necessary to reduce the mass since the structure doesn't work better after being optimized.

\section{CONCLUSION}

In this work, an optimal design based on Kriging interpolation algorithm for a robotic arm is developed, and being implemented parallel with the dynamics simulating model [11]. The structure is tested under evaluation criteria of maximum strain(or stress), useful life and safety factor. The results generated by integrated finite element analyses completely meet the technological requirements.

Thus, this paper presents an efficient Kriging interpolation algorithm-based methodology for structural dynamic analysis of a 6-DOF robot arm using ANSYS workbench 13 simulation software, which allows visualization of the distribution of stress or strain from each work-position under different safety-factors and applied moments, and enables integrated optimization of the robot arm's mechanical structure in terms of materials and shape. Therefore, It makes this project novel and meaningful. But in this paper, we didn't take all conditions into account yet, they will be analyzed in the future work. 
The result shows more economic and efficient structures that will meet desired operation specifications. The performance of a pair of gears depends on the loading distribution across the tooth width and profile. A precise computation of the load distribution is critical in optimizing the strength and running-behavior of spur gears. A nonuniform load distribution is generally caused by manufacturing and assembly errors, and elastic deformation of the transmission shafts, the bearing, and the abutment. Several parts of the prototype were conducted analytically, and the results obtained are consistent with real conditions. So that not only the novel prototype but also the simulation is reasonable and believable, which means the analysis results obtained can be used in further cases.

\section{CONFLICT OF INTEREST}

The authors confirm that this article content has no conflict of interest.

\section{ACKNOWLEDGEMENTS}

This work is partially supported by the National Natural Science Foundation of China (Grant No.51175187), also by the National High-Tech R\&D Program of China (Grant No. 2007AA04Z111).

\section{REFERENCES}

[1] R. L. Mott. Machine element design (4th ed.) Prentice Hall. 2006.

[2] D.A. Hancq, A.J. Walters, J.L. Beuth, "Development of an ObjectOriented Fatigue Tool", Engineering with Computers, vol. 16, pp. 131-144, 2000.

[3] http://www.testdevices.com/services/rotor_spin_testing/low_cycle fatigue testing.

[4] A. Guinta and L. Watson, "A comparison of approximation modeling techniques: polynomial versus interpolating models," Proc. of the 7th AIAA/ USAF/NASA/ISSMO Symposium on Multidisciplinary Analysis and Optimization, St. Louis, USA. 2 392-440 (AIAA-98-4758). 1998.

[5] T. J. Santner, B. J. Williams, and W. I. Notz, "The Design and Analysis of Computer Experiments," Springer, New York, 2003.

[6] K. H. Lee and D. H. Kang, "A robust optimization using the statistics based on kriging metamodel," Journal of Mechanical Science and Technology, vol. 20, no. 8, pp. 1169-1182, 2006.

[7] S. Jun, Y. H. Jeon and D. H. Lee, "Application of collaborative optimization using response surface methodology to an aircraft wing design" [ $\mathrm{C}$ ] // 10th AIAA/ IS SMO Multidisciplinary Analysis and Optimization Conference. AIAA 2004 4442, 30 August -1 September 2004.

[8] S.N. Lophaven, H.B. Nielsen, J. Sondergard. DACE ( A Mat lab Kriging toolbox, version 2.0 [OL]. http://www.Imm.Dtu.dk/ hbn/pub1/TR0212.ps

[9] N.A.C. Cressie. Statistics for spatial data. Revised ed. New York: Wiley, 1993.

[10] H. Wackernagel. Multivariate geostatistics: An introduction with applications. New York, USA: Springer, 2003.

[11] D.S. Bae, J.K. Lee, "An explicit integration method for realtime simulation of multibody vehicle models", Computer methods in applied mechanics and engineering, vol. 187, no. 1-2, pp. 337-350, 2000.

Received: November 11, 2013

Revised: February 11, 2014

Accepted: March 3, 2014

(C) Li et al.; Licensee Bentham Open.

This is an open access article licensed under the terms of the Creative Commons Attribution Non-Commercial License (http://creativecommons.org/licenses/ by-nc/4.0/) which permits unrestricted, non-commercial use, distribution and reproduction in any medium, provided the work is properly cited. 